\title{
The Relation between Plasma Concentrations of Glutamine and Glycine and Utilization of Their Nitrogens as Sources of Urinary Ammonia *
}

\author{
Robert F. Pitts $\dagger$ and Lou Ann Pilkington $\ddagger$ \\ (From the Department of Physiology and Biophysics, Cornell University Medical College, \\ New York, N.Y.)
}

The infusion of a number of amino acids into a peripheral vein or renal artery increases the rate of urinary excretion of ammonia in acidotic dogs (1-3). According to Lotspeich (4), amino acids fall into three groups: those that greatly augment the excretion of ammonia, such as glutamine, asparagine, alanine, and histidine; those that moderately augment the excretion of ammonia, such as glycine, leucine, aspartic acid, and methionine; and those that do not appreciably affect the excretion of ammonia, such as glutamic acid, lysine, and arginine. The inference that those amino acids that increase the excretion of ammonia when infused intravenously are the immediate precursors of urinary ammonia under normal conditions is not necessarily correct, for blood ammonia increases sharply when amino acids are infused at the high rates employed in many of these studies (5). Thus a part of the increased urinary ammonia might be derived from preformed ammonia produced elsewhere and delivered to the kidneys in the arterial blood. Furthermore the renal tubular precursor of ammonia, which is utilized in increased quantity, might not be solely the amino acid infused but, in part, another formed at some extrarenal site by transamination. A further possible complication is a reduction in the utilization of the nitrogen of one precursor, e.g., glutamine, when the plasma concentration of another precursor, e.g., glycine or alanine, is increased. It is known that certain amino acids compete in renal

\footnotetext{
* Submitted for publication July 15, 1965; accepted October 4, 1965.

Aided by grants from the National Heart Institute and the Life Insurance Medical Research Fund.

† Address requests for reprints to Dr. Robert F. Pitts, Dept. of Physiology, Cornell University Medical College, 1300 York Ave., New York, N. Y. 10021.

$\ddagger$ Research trainee of the National Heart Institute.
}

tubular reabsorptive transport $(6,7)$. They might also compete as precursors of ammonia.

Recent experiments with ${ }^{15} \mathrm{~N}$-labeled amino acids (8) have demonstrated that 35 to $50 \%$ of the urinary ammonia is normally derived from the amide nitrogen and 16 to $25 \%$ from the amino nitrogen of plasma glutamine. Much smaller proportions are derived from plasma glycine and glutamic acid, namely 3 to $4 \%$ and 1 to $2 \%$, respectively. The experiments reported in this paper demonstrate the following facts: When the plasma concentration of glutamine is increased over a fourfold range, both amide and amino nitrogens are utilized in increasing amounts as precursors of ammonia. Glycine nitrogen is similarly the source of much of the extra ammonia excreted when the plasma concentration of glycine is modestly increased. Moderate elevation of plasma glycine or alanine does not reduce the utilization of the amino or amide nitrogens of glutamine as sources of urinary ammonia. Rather, small increases in utilization occur that are probably related to the increase in plasma concentration of glutamine that accompanies the infusion of alanine and, less consistently, the infusion of glycine.

\section{Methods}

The 16 experiments that constitute the basis of this paper were performed on mongrel dogs of either sex lightly anesthetized with intravenous pentobarbital. Acidosis was induced by the feeding of $10 \mathrm{~g}$ of ammonium chloride mixed with food each day for 3 days before the experiment. The ureters were catheterized through a low midline abdominal incision, and the tips of the catheters were advanced to the estimated level of the renal pelvis. A curved no. 25 needle was introduced into one renal artery, usually the left, exposed retroperitoneally through a flank incision: A ${ }^{15} \mathrm{~N}$-labeled amino acid dissolved in saline containing a small amount of heparin was infused into the renal artery at a constant rate of 5 to $10 \mu$ moles per minute for 15 minutes before 
TABLE I

The utilization of the amino nitrogen of glutamine as a precursor of urinary ammonia at normal and elevated plasma concentrations of glutamine*

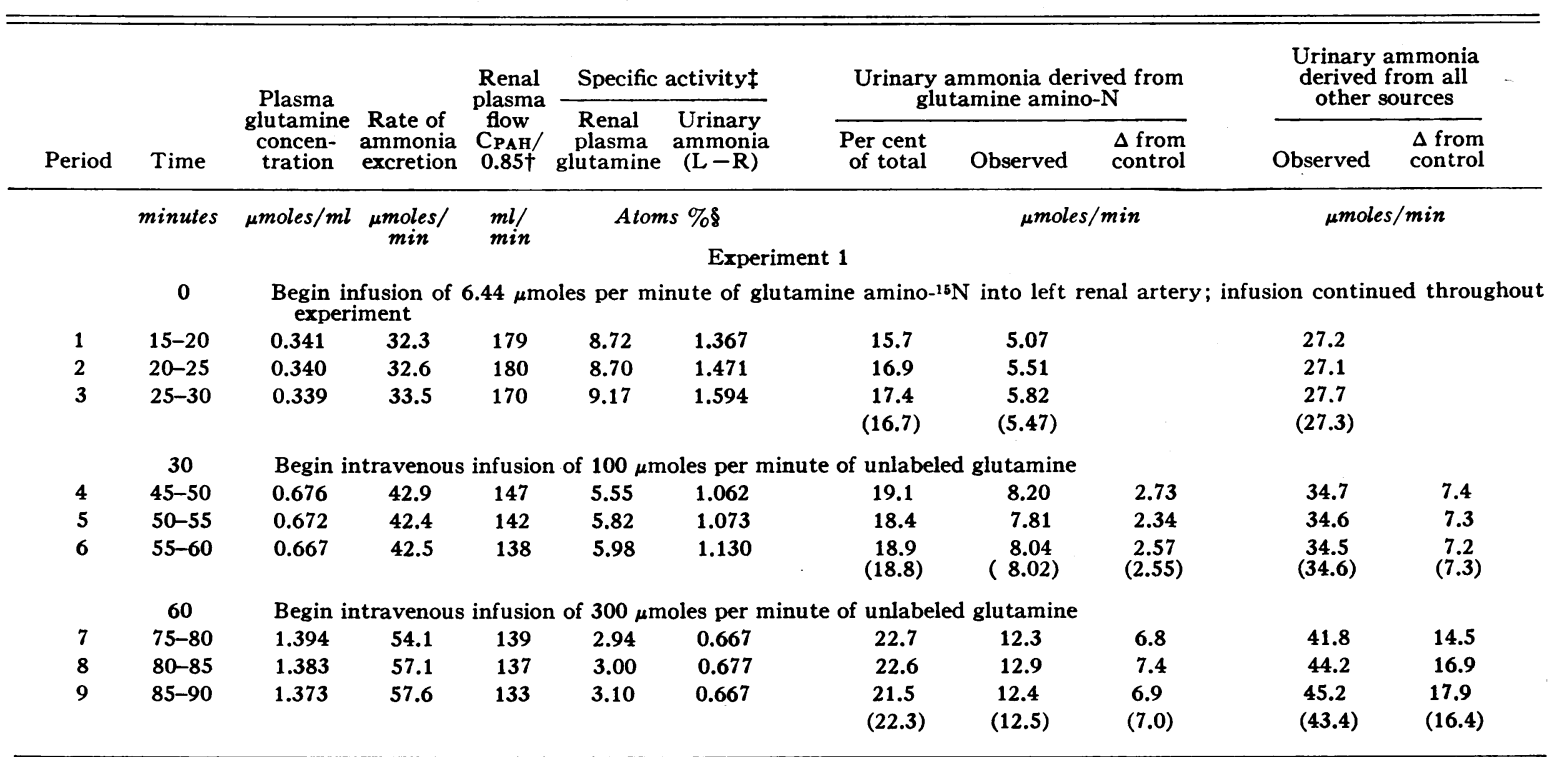

* Results obtained in an experiment on an acidotic dog.

$+\mathrm{CPAB}_{\mathrm{PA}} \mathbf{0 . 8 5}=$ clearance of $p$-aminohippurate, corrected for an average extraction of $\mathbf{8 5 \%}$.

$\ddagger$ Specific activity of renal plasma glutamine is calculated; $L-R=$ left kidney minus right kidney.

$\$$ Of ${ }^{16} \mathrm{~N}$ excess.

the start of the first collection period and throughout the entire experiment. Creatinine for measurement of glomerular filtration rate, $p$-aminohippurate for measurement of renal plasma flow, and an unlabeled amino acid, as noted in each experimental protocol, were incorporated into an intravenous infusion administered at a rate of $5 \mathrm{ml}$ per minute. The infusion was made twothirds isotonic by addition of sodium sulfate to ensure the excretion of acid urine. All urine $\mathrm{pH}$ 's were within a range of 4.8 to 5.8. Since, in the course of any one experiment, $\mathrm{pH}$ did not vary significantly, values are not reported.

Chemical methods, including the preparation of ${ }^{15} \mathrm{~N}$ labeled amino acids and the analysis of the isotopic content of urinary ammonia, are given in detail in a preceding publication (8).

\section{Results}

The basic plan of the experiments reported in this paper is illustrated by the one summarized in Table I. Fifteen minutes before the first collection period, an intra-arterial infusion of amino- ${ }^{15} \mathrm{~N}$-labeled glutamine (92 atoms \%) was begun and continued at a constant rate of $6.44 \mu$ moles per minute throughout the experiment. Urine collection periods were 5 minutes in length; the first three constituted control observations. Immediately after the third collection period, unlabeled glutamine was incorporated in the intravenous in- fusion and administered at a rate of $100 \mu$ moles per minute. A priming dose of glutamine was also given. After 15 minutes, to permit the plasma glutamine concentration to stabilize, three more urine samples were collected. Again, the infusion was changed, and unlabeled glutamine was given as a prime and infused at a rate of $300 \mu$ moles per minute.

Arterial blood samples were drawn at the midpoints of periods $1,3,4,6,7$, and 9. Plasma concentrations of creatinine, $p$-aminohippurate, and glutamine were measured and values interpolated at the midpoints of periods 2,5 , and 8 . The clearance of $p$-aminohippurate, corrected for an average extraction of $85 \%$, was accepted as a measure of renal plasma flow (8).

The ${ }^{15} \mathrm{~N}$ content of the ammonia excreted by the left infused kidney was of course greater than it was in that excreted by the right control kidney. The latter represents the contribution of the ${ }^{15} \mathrm{~N}$ of those compounds made equally available to both kidneys as a consequence of recirculation, not only the ${ }^{15} \mathrm{~N}$ of the originally administered glutamine, but also the ${ }^{15} \mathrm{~N}$ of precursors in any form. The difference between the atoms per cent excess ${ }^{15} \mathrm{~N}$ in the ammonia excreted by the left and right kid- 
neys is therefore an expression of the specific activity ${ }^{1}$ of the urinary ammonia, due solely to the infusion of labeled glutamine into the left renal artery. The specific activity of the plasma glutamine delivered to the left kidney as a consequence of the infusion of labeled compound was calculated as the quotient of the amino- ${ }^{15} \mathrm{~N}$ excess (micromoles per minute) infused into the left renal artery and the total glutamine load to the left kidney (micromoles per minute). The total glutamine load to the left kidney is the sum of the infused load and the perfused load; the latter is the product of the renal plasma flow and the arterial plasma glutamine concentration. The plasma specific activity, like the urine specific activity, is thus independent of recirculated ${ }^{15} \mathrm{~N}$ in any form (8). Dividing the specific activity of the urinary ammonia (left minus right) by the specific activity of the plasma glutamine delivered to the left kidney and multiplying by 100 yields the per cent of the urinary ammonia derived from the amino- $\mathrm{N}$ of circulating

1 The term specific activity is properly used only in dealing with radioactive isotopes. However, because it is well understood, we elect to use it in dealing with the stable isotope, ${ }^{15} \mathrm{~N}$, in lieu of "degree of enrichment," which might lead to some confusion. plasma glutamine. A detailed description of the calculations and the underlying assumptions is given in a preceding paper (8).

It is evident from the data of Table I that in the three control periods, at a low normal plasma glutamine concentration, an average of $16.7 \%$ of the urinary ammonia was derived from the amino- $\mathrm{N}$ of circulating plasma glutamine, a value within the range observed by Pitts, Pilkington, and De Haas (8). The intravenous infusion of unlabeled glutamine to double and then to quadruple plasma concentration ${ }^{2}$ resulted in increases in rate of ammonia excretion from 32 to 42 and then to 57 $\mu$ moles per minute. The percentage of this ammonia derived from the amino nitrogen of glutamine increased modestly from $16.7 \%$ to $22.3 \%$.

The product of the rate of excretion of ammonia and its per cent of derivation from the amino- $\mathrm{N}$

\footnotetext{
${ }^{2}$ In no instance was the excretion of glutamine in the urine greater than $0.15 \mu$ mole per minute, a negligibly small value. Less than $2 \%$ of that excreted would be broken down to form ammonia during the removal of ammonia by the technique of Van Slyke and Cullen. Since the atoms per cent excess ${ }^{15} \mathrm{~N}$ of such ammonia would be no greater than that of the glutamine of plasma, no measurable error is introduced as chemical artefact.
}
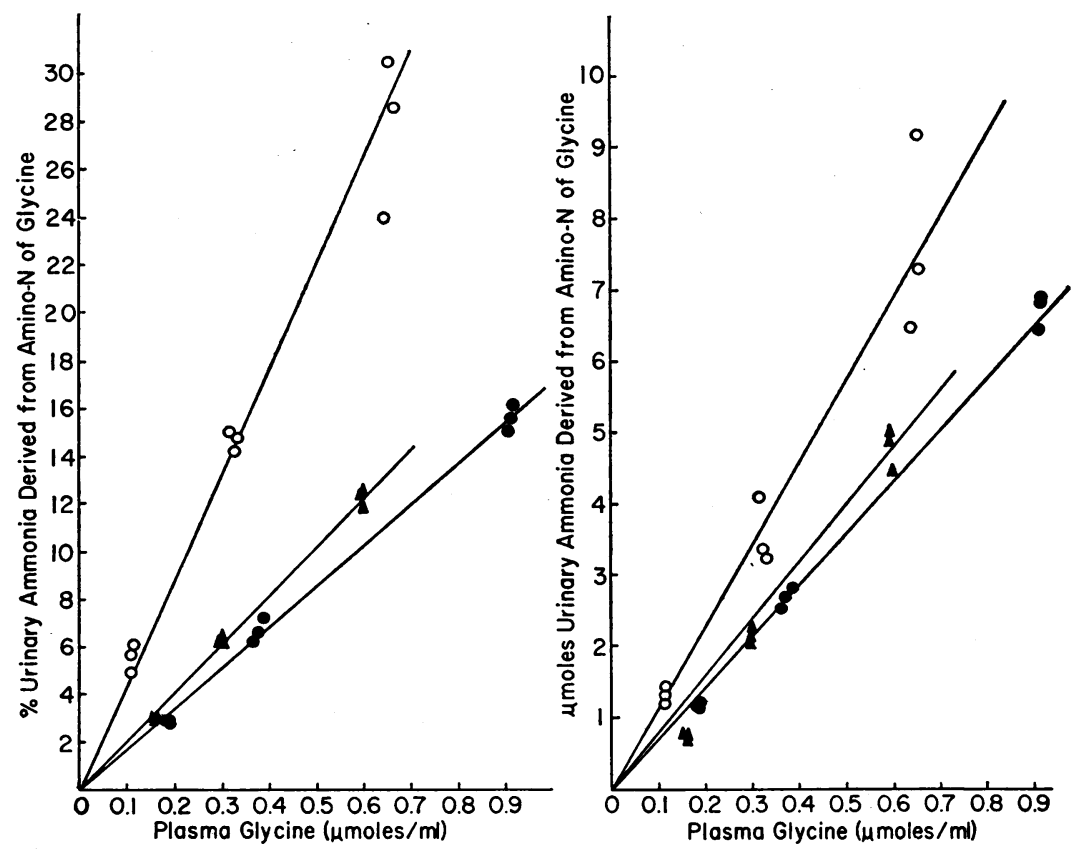

Fig. 1. The utilization of the amino Nitrogen of glycine as a PReCURSOR OF URINARY AMMONIA AT NORMAL AND ELEVATED PLASMA CONCENTRATIONS OF GLYCINE. Results obtained in three experiments on acidotic dogs. 

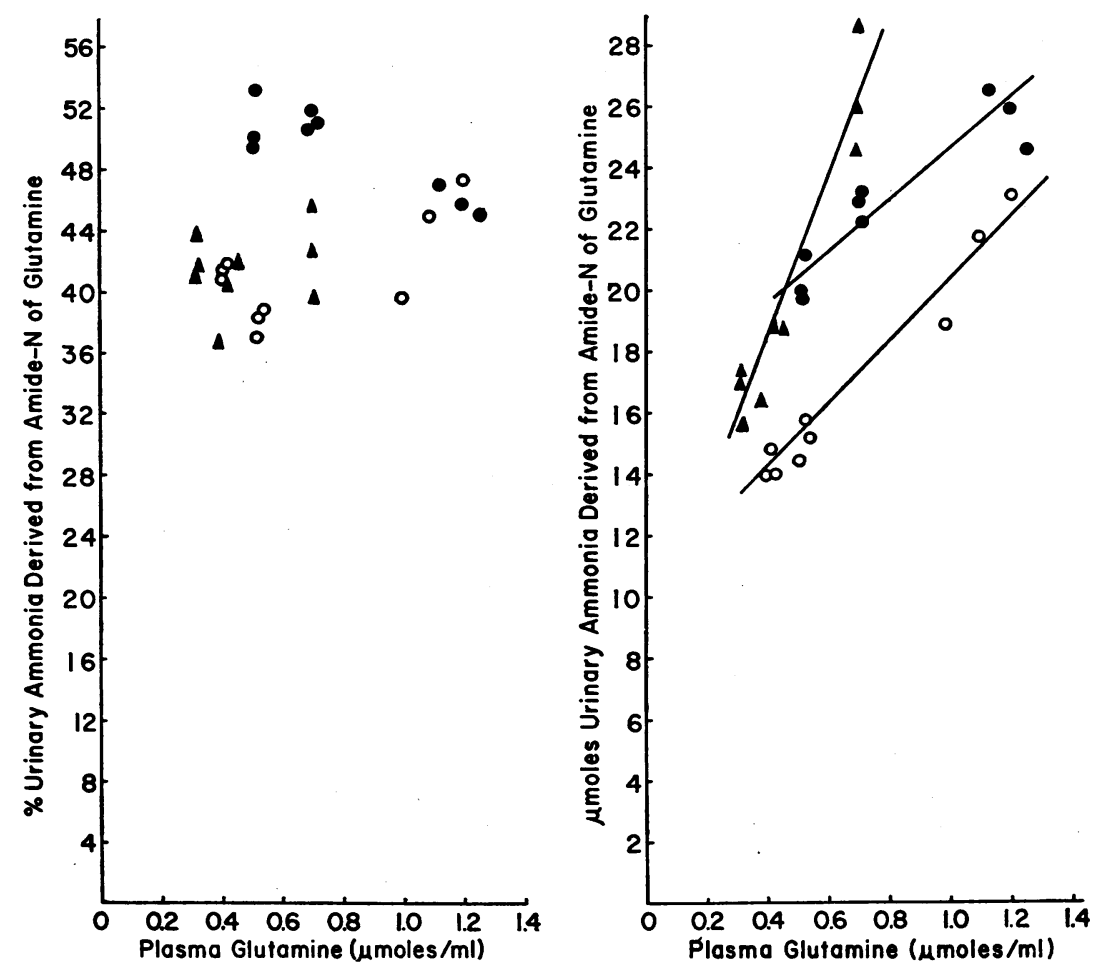

Fig. 2. The Utilization of the AMIDE NItrogen of GLUTAMine as a PRECURSOR OF URINARY AMMONIA AT NORMAL AND ELEVATED PLASMA CONCENTRATIONS OF GLUTAMINE. Results obtained in three experiments on acidotic dogs.

of glutamine gives the observed rate at which the amino nitrogen of this precursor is incorporated into urinary ammonia. The ammonia so derived increased from 5.47 to 8.02 and then to 12.5 $\mu$ moles per minute with increasing plasma glutamine concentration. The difference between the total rate of excretion of ammonia and the rate of excretion of that derived from the amino nitrogen of glutamine gives the rate of excretion of the ammonia that originates from all other precursors. It is apparent from Table $I$ that the rate of excretion of ammonia derived from all other precursors increased about twice as much relative to control as did the rate of excretion of ammonia derived from the amino- $\mathrm{N}$ of glutamine. Obviously, the rate of excretion of ammonia derived from all other precursors includes as the major contribution that from the amide- $\mathrm{N}$ of glutamine. Our findings, therefore, are consonant with the thesis of Pitts and co-workers (8) that, over the normal range of plasma concentration, approximately twice as much of the urinary ammonia is derived from the amide- $\mathrm{N}$ as from the amino- $\mathrm{N}$ of plasma glutamine.

Figures 1 to 3 summarize the results of eight experiments performed in a manner similar to the one presented in Table I. Note that the vertical scale of Figure 2 is half that of Figures 1 and 3. In these experiments, the contributions of the amino and the amide nitrogens of glutamine and the amino nitrogen of glycine to urinary ammonia were studied over limited ranges of plasma concentration of glutamine and glycine, respectively. It is evident from these Figures that the absolute derivation of ammonia in micromoles per minute from each of these sources increased with increasing plasma concentration. However, the changes in the per cent of contribution of each of the three precursors to ammonia excretion differed considerably. The per cent contribution of glycine to total ammonia excretion increased markedly, that of the amino- $\mathrm{N}$ of glutamine increased moderately, and that of the amide- $\mathrm{N}$ of glutamine exhibited no consistent change. These findings are 
probably more arithmetical than functional in origin. The per cent of the ammonia derived from glycine- $\mathrm{N}$ in the control periods ( 3 points to the left of each series) was low, between 2.5 and $6 \%$. The per cent derived from the amino- $\mathrm{N}$ of glutamine was intermediate (10 to $18 \%$ ), and the per cent derived from the amide- $\mathrm{N}$ of glutamine was high (36 to 54\%). A given absolute increase in ammonia output derived from each of the amino acids infused therefore would result in a marked increase in percentage when glycine- $\mathrm{N}$ was the source studied, a modest increase when the amino- $N$ of glutamine was the source studied, and a small increase when the amide- $\mathrm{N}$ of glutamine was the source studied. A small increase in percentage of utilization of the amide- $\mathrm{N}$ of glutamine probably occurred, but it was obscured by uncontrolled variables in the experiments summarized in Figure 2.

Table II summarizes four experiments in which the effects of increasing the plasma concentration of glycine or alanine on the utilization of the amide or amino nitrogens of glutamine as sources of urinary ammonia were assessed. Similar results were obtained in four other experiments. Periods 1 to 3 of each experiment constitute control observations made before the infusion of either glycine or alanine. During periods 4 to 6 , one or the other of these amino acids, as noted, was infused at a rate of $100 \mu$ moles per minute. During periods 7 to 9 , the rate of infusion was increased to $300 \mu$ moles per minute. In these experiments the percentages of the urinary ammonia derived from the amide- $N$ of glutamine fell within the range defined by Pitts and associates (8), namely 35 to $50 \%$. Similarly, the percentages of the urinary ammonia derived from the amino- $\mathrm{N}$ of glutamine fell within the defined range of 15 to $25 \%$.

Elevation of the plasma concentrations of glycine and of alanine increased the urinary excretion of ammonia. Presumably, much of this extra ammonia was derived directly from the infused amino acid. However, in no instance, including four other experiments similar to those of Table II, was the utilization of the amide or amino nitrogens of glutamine reduced. Rather, in all experiments, utilization of these precursor nitrogens was slightly to modestly increased. In all of the experiments
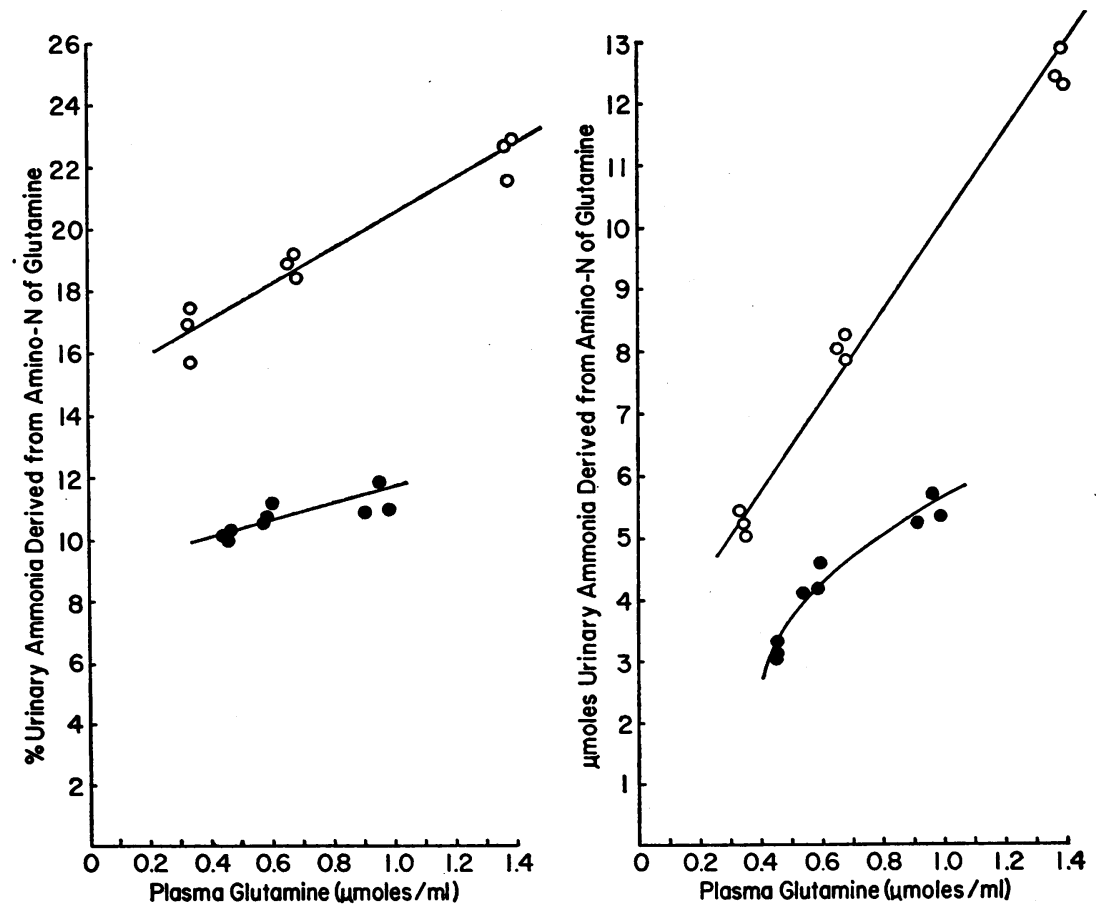

Fig. 3. The utilization of the amino Nitrogen of glutamine as a PRECURSOR OF URINARY AMMONIA AT NORMAL AND ELEVATED PLASMA CONCENTRATIONS OF GLUTAMINE. Results obtained in two experiments on acidotic dogs. 
TABLE II

The effects of increasing plasma concentrations of glycine and alanine on the utilization of the amide and amino nitrogens of circulating plasma glutamine as precursors of urinary ammonia*

\begin{tabular}{|c|c|c|c|c|c|c|c|c|c|}
\hline \multirow[b]{2}{*}{ Period } & \multirow[b]{2}{*}{ Time } & \multirow{2}{*}{$\begin{array}{l}\text { Plasma } \\
\text { glutamine } \\
\text { concen- } \\
\text { tration }\end{array}$} & \multirow{2}{*}{$\begin{array}{l}\text { Plasma } \\
\text { concentra- } \\
\text { tion of } \\
\text { amino acid } \\
\text { infused }\end{array}$} & \multirow{2}{*}{$\begin{array}{l}\text { Rate of } \\
\text { ammonia } \\
\text { excretion }\end{array}$} & \multicolumn{3}{|c|}{$\begin{array}{l}\text { Urinary ammonia derived from } \\
\text { glutamine-nitrogen studied }\end{array}$} & \multicolumn{2}{|c|}{$\begin{array}{l}\text { Urinary ammonia de- } \\
\text { rived from all other } \\
\text { sources }\end{array}$} \\
\hline & & & & & $\begin{array}{l}\text { Per cent } \\
\text { of total }\end{array}$ & Observed & $\begin{array}{l}\Delta \text { from } \\
\text { control }\end{array}$ & Observed & $\begin{array}{l}\Delta \text { from } \\
\text { control }\end{array}$ \\
\hline & minutes & $\mu m o l e / m l$ & 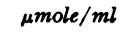 & $\begin{array}{c}\text { Amoles/ } \\
\text { min }\end{array}$ & & \multicolumn{2}{|c|}{$\mu$ moles/min } & \multicolumn{2}{|c|}{$\mu m o l e s / \min$} \\
\hline \multicolumn{10}{|c|}{ Experiment 2. Utilization of the amide- $\mathrm{N}$ of glutamine during the infusion of glycine } \\
\hline & & \multicolumn{3}{|c|}{ Glycine } & Amide- $\mathrm{N}$ & & & & \\
\hline $\begin{array}{l}1 \\
2 \\
3\end{array}$ & $\begin{array}{l}15-20 \\
20-25 \\
25-30\end{array}$ & $\begin{array}{l}0.371 \\
0.368 \\
0.364\end{array}$ & $\begin{array}{l}0.170 \\
0.168 \\
0.166\end{array}$ & $\begin{array}{l}36.2 \\
37.3 \\
37.2\end{array}$ & $\begin{array}{c}44.8 \\
46.2 \\
44.4 \\
(45.1)\end{array}$ & $\begin{array}{c}16.2 \\
17.2 \\
16.5 \\
(16.6)\end{array}$ & \multicolumn{3}{|c|}{$\begin{array}{c}20.0 \\
20.1 \\
20.7 \\
(20.3)\end{array}$} \\
\hline 4 & 45-50 & 0.386 & 0.347 & 40.6 & 43.9 & 17.8 & 1.2 & 22.8 & 2.5 \\
\hline 5 & $50-55$ & 0.394 & 0.362 & 41.9 & 42.2 & 17.7 & 1.1 & 24.2 & 3.9 \\
\hline 6 & $55-60$ & 0.401 & 0.376 & 42.7 & $\begin{array}{c}44.7 \\
(43.6)\end{array}$ & $\begin{array}{c}19.1 \\
(18.2)\end{array}$ & $\begin{array}{l}2.5 \\
(1.6)\end{array}$ & $\begin{array}{c}23.6 \\
(23.5)\end{array}$ & $\begin{array}{c}3.3 \\
(3.2)\end{array}$ \\
\hline 7 & $75-80$ & 0.417 & 0.871 & 51.9 & 38.2 & 19.8 & 3.2 & 32.1 & 11.8 \\
\hline 8 & $80-85$ & 0.413 & 0.894 & 51.4 & 38.0 & 19.5 & 2.9 & 31.9 & 11.6 \\
\hline 9 & $85-90$ & 0.409 & 0.916 & 51.0 & $\begin{array}{c}35.0 \\
(37.1)\end{array}$ & $\begin{array}{c}18.3 \\
(19.2)\end{array}$ & $\begin{array}{c}1.7 \\
(2.6)\end{array}$ & $\begin{array}{c}32.7 \\
(32.2)\end{array}$ & $\begin{array}{c}12.4 \\
(11.9)\end{array}$ \\
\hline
\end{tabular}

Experiment 3. Utilization of the amino- $\mathrm{N}$ of glutamine during the infusion of glycine

\begin{tabular}{|c|c|c|c|c|c|c|c|c|}
\hline & & Glycine & & Amino-N & & & & \\
\hline $15-30$ & 0.571 & 0.121 & 40.5 & 16.3 & 6.60 & & 33.9 & \\
\hline $20-25$ & 0.580 & 0.125 & 43.1 & 16.5 & 7.11 & & 36.0 & \\
\hline $25-30$ & 0.589 & 0.129 & 41.6 & $\begin{array}{c}16.6 \\
(16.5)\end{array}$ & $\begin{array}{c}6.91 \\
(6.87)\end{array}$ & & $\begin{array}{c}34.7 \\
(34.9)\end{array}$ & \\
\hline $45-50$ & 0.555 & 0.289 & 47.6 & 17.5 & 8.33 & 1.46 & 39.3 & 4.4 \\
\hline $50-55$ & 0.550 & 0.301 & 49.1 & 18.4 & 9.03 & 2.16 & 40.1 & 5.2 \\
\hline $55-60$ & 0.544 & 0.313 & 49.8 & $\begin{array}{c}19.1 \\
(18.3)\end{array}$ & $\begin{array}{c}9.52 \\
(8.96)\end{array}$ & $\begin{array}{c}2.65 \\
(2.09)\end{array}$ & $\begin{array}{c}40.3 \\
(39.9)\end{array}$ & $\begin{array}{c}5.4 \\
(5.0)\end{array}$ \\
\hline $75-80$ & 0.560 & 0.813 & 54.0 & 21.3 & 11.5 & 4.63 & .42 .5 & 7.6 \\
\hline $80-85$ & 0.548 & 0.802 & 50.2 & 20.0 & 10.0 & 3.13 & 40.2 & 5.3 \\
\hline $85-90$ & 0.536 & 0.792 & 53.8 & $\begin{array}{c}19.9 \\
(20.4)\end{array}$ & $\begin{array}{c}10.7 \\
(10.7)\end{array}$ & $\begin{array}{c}3.83 \\
(3.86)\end{array}$ & $\begin{array}{c}43.1 \\
(41.9)\end{array}$ & $\begin{array}{c}8.2 \\
(7.0)\end{array}$ \\
\hline
\end{tabular}

Experiment 4. Utilization of the amide- $\mathrm{N}$ of glutamine during the infusion of alanine

\begin{tabular}{lrrrr} 
& & \multicolumn{3}{c}{ Alanine } \\
1 & $15-20$ & 0.416 & 0.127 & 41.3 \\
2 & $20-25$ & 0.404 & 0.126 & 42.3 \\
3 & $25-30$ & 0.392 & 0.125 & 44.1 \\
4 & $45-50$ & 0.423 & 0.245 & 44.6 \\
5 & $50-55$ & 0.418 & 0.246 & 48.7 \\
6 & $55-60$ & 0.413 & 0.246 & 49.0 \\
7 & $75-80$ & 0.466 & 0.473 & 51.3 \\
8 & $80-85$ & 0.473 & 0.483 & 50.1 \\
9 & $85-90$ & 0.480 & 0.493 & 50.3
\end{tabular}

Amide-N

Experiment 5. Utilization of the amino- $\mathrm{N}$ of glutamine during the infusion of alanine

$\begin{array}{ccccc}46.0 & 19.0 & & 22.3 & \\ 46.5 & 19.7 & & 22.6 & \\ 47.5 & 20.9 & & 23.2 & \\ (46.7) & (19.7) & & (22.7) & \\ 46.4 & 20.7 & 1.0 & 23.9 & 1.2 \\ 50.4 & 24.6 & 4.9 & 24.1 & 1.4 \\ 49.5 & 24.3 & 4.6 & 24.7 & 2.0 \\ (48.8) & (23.2) & (3.5) & (24.2) & (1.5) \\ 42.2 & 21.7 & 2.0 & 29.6 & 6.9 \\ 44.3 & 22.2 & 2.5 & 27.9 & 5.2 \\ 47.3 & 23.8 & 4.1 & 26.5 & 3.8 \\ (44.6) & (22.6) & (2.9) & (28.0) & (5.3)\end{array}$

Alanine

$\begin{array}{lllll}1 & 15-20 & 0.432 & 0.203 & 55.8 \\ 2 & 20-25 & 0.422 & 0.208 & 56.3 \\ 3 & 25-30 & 0.411 & 0.214 & 60.1 \\ & & & & \\ 4 & 45-50 & 0.484 & 0.606 & 73.1 \\ 5 & 50-55 & 0.481 & 0.638 & 71.4 \\ 6 & 55-60 & 0.478 & 0.671 & 74.8 \\ 7 & 75-80 & 0.547 & 1.06 & 73.2 \\ 8 & 80-85 & 0.529 & 1.06 & 76.1 \\ 9 & 85-90 & 0.511 & 1.06 & 75.7\end{array}$

Amino-N

$\begin{array}{ccccc}25.0 & 14.0 & & 41.8 & \\ 26.3 & 14.8 & & 41.5 & \\ 25.3 & 15.2 & & 44.9 & \\ (25.5) & (14.7) & & (42.7) & \\ 26.0 & 19.0 & 4.3 & 54.1 & 11.4 \\ 25.4 & 18.1 & 3.4 & 53.3 & 10.6 \\ 25.1 & 18.8 & 4.1 & 56.0 & 13.3 \\ (25.5) & (18.6) & (3.9) & (54.5) & (11.8) \\ 23.3 & 17.1 & 2.4 & 56.1 & 13.4 \\ 23.8 & 18.1 & 3.4 & 58.0 & 15.3 \\ 22.6 & 17.1 & 2.4 & 58.6 & 15.9 \\ (23.2) & (17.4) & (2.7) & (57.6) & (14.9)\end{array}$

* Results obtained in four experiments on acidotic dogs. 
in which alanine was infused, the plasma concentration of glutamine increased significantly, a fact that adequately explains the increased utilization of its amino and amide nitrogens. However, no increase in plasma concentration of glutamine occurred in experiment three, in which glycine was infused, and in which utilization of the amino- $\mathrm{N}$ of glutamine also increased. Whether the increased utilization of the amino and amide nitrogens of glutamine after the infusion of glycine is significant and causally related to an increase in plasma glutamine concentration is, therefore, uncertain. Because the increases are small, a large number of experiments would be required to establish their reality, if indeed they are real.

\section{Discussion}

The data presented in this paper demonstrate that a modest increase in plasma concentration of glutamine results in increased utilization of both its amide and amino nitrogens as sources of urinary ammonia in acidotic dogs. According to Shalhoub and co-workers (9) the mean arterial plasma concentration of glutamine in acidotic dogs is $0.450 \pm 0.093$ (SD) $\mu$ mole per $\mathrm{ml}$, with upper and lower limits of 0.633 and $0.258 \mu$ mole per $\mathrm{ml}$, respectively. Such variations in plasma concentration would therefore be expected to be accompanied by variations in the amounts of amino and amide nitrogen utilized for ammonia production.

Whether the plasma concentration of glutamine is increased in acidosis in comparison with the normal is controversial $(10,11)$. In any event the increase is small and could not explain the large differences in renal ammonia production in these two conditions. Rather the much greater extraction of glutamine by the kidneys in acidosis than in normal acid-base balance $(9,10,12,13)$ must be more significantly related to the increased ammonia production. Since the arterial plasma concentration of glutamine is not greatly different in acidosis and in normal acid-base balance, it is evident that the rate of corporeal production of glutamine must increase in acidosis to balance increased renal utilization.

According to Shalhoub and co-workers (9), the plasma concentration of glycine in acidotic dogs averages $0.169 \pm 0.046$ (SD) $\mu$ mole per $\mathrm{ml}$ with upper and lower limits of 0.272 and $0.080 \mu$ mole per ml. Again, over such a range one would predict small changes in utilization of glycine- $\mathrm{N}$ in the production of urinary ammonia (cf. Figure 3 ).

Although a generalization based on studies of two amino acids is far from firmly established, we assume that a major fraction of the increased urinary ammonia, excreted in consequence of a modest increase in the plasma concentration of any one amino acid, is derived within the kidney from that amino acid. This view is certainly not true if plasma concentration is so markedly elevated as to lead to an increase in arterial ammonia concentration (5). Furthermore, even when plasma concentration is only moderately elevated, it probably is not true that all of the extra ammonia excreted is derived intrarenally from the amino acid infused. This follows from the observation that the infusion of alanine increased the plasma concentration of glutamine and resulted in the utilization of additional amide and amino nitrogen of this source material for production of urinary ammonia. The same was true in one experiment in which glycine was infused.

Increased utilization of glycine and alanine nitrogen for ammonia production did not reduce the utilization of either the amide or amino nitrogens of glutamine. We had anticipated some competitive interaction of alanine and the amino- $\mathrm{N}$ of glutamine in line with the view that most amino acids other than glycine contribute to ammonia production by transamination of $\alpha$-ketoglutarate to form glutamate and by subsequent oxidative desamination of glutamate to liberate ammonia (2). Failure of increased utilization of alanine to suppress the utilization of the amino nitrogen of glutamine does not negate this view. It probably only means that substrate availability (uptake of amino acid by cells) rather than enzyme saturation limits ammonia production within the range of plasma concentrations employed in our studies.

\section{Summary}

The intravenous infusion of glycine to increase plasma concentration over a range of 0.15 to 1.0 $\mu$ mole per $\mathrm{ml}$ is accompanied by an increase in rate of urinary excretion of ammonia. This extra ammonia is essentially a linear function of plasma glycine concentration and in major part is derived intrarenally from glycine. The intravenous infu- 
sion of glutamine to increase plasma concentration over a range of 0.3 to $1.4 \mu$ moles per $\mathrm{ml}$ is similarly accompanied by an increase in ammonia excretion, which is more or less linearly related to plasma glutamine concentration. This extra ammonia is also largely derived from the amide and amino nitrogens of glutamine. Within this range of plasma concentration, approximately twice as much ammonia is derived from the amide as from the amino nitrogen of glutamine. Modest elevation of the plasma concentration of either glycine or alanine does not reduce the utilization of either the amide or the amino nitrogens of glutamine as precursors of urinary ammonia. Rather, the amide and amino nitrogens are utilized in slightly greater amounts, which may or may not be quantitatively significant. Elevation of plasma alanine increased plasma glutamine concentration to a small but significant degree, a fact that may be responsible for the observed increase in utilization of the amide and amino nitrogens of glutamine for production of urinary ammonia.

\section{References}

1. Lotspeich, W. D., and R. F. Pitts. The role of amino acids in the renal tubular secretion of ammonia. J. biol. Chem. 1947, 168, 611.

2. Kamin, H., and P. Handler. The metabolism of parenterally administered amino acids. III. Ammonia formation. J. biol. Chem. 1951, 193, 873.

3. Canessa-Fischer, M., R. Shalhoub, S. Glabman, J. DeHaas, and R. F. Pitts. Effects of infusions of ammonia, amides, and amino acids on excretion of ammonia. Amer. J. Physiol. 1963, 204, 192.

4. Lotspeich, W. D. Metabolic Aspects of Renal Function. Springfield, Ill., Charles C Thomas, 1959, p. 92.
5. Du Ruisseau, J. P., J. P. Greenstein, M. Winitz, and S. M. Birnbaum. Studies on the metabolism of amino acids and related compounds in vivo. IV. Blood ammonia and urea levels following intraperitoneal administration of amino acids and ammonium acetate, and the effect of arginine thereon. Arch. Biochem. 1956, 64, 355.

6. Brown, J. L., A. H. Samiy, and R. F. Pitts. Localization of amino-nitrogen reabsorption in the nephron of the dog. Amer. J. Physiol. 1961, 200, 370.

7. Webber, W. A., J. L. Brown, and R. F. Pitts. Interactions of amino acids in renal tubular transport. Amer. J. Physiol. 1961, 200, 380.

8. Pitts, R. F., L. A. Pilkington, and J. C. M. de Haas. $\mathrm{N}^{15}$ tracer studies on the origin of urinary ammonia in the acidotic dog, with notes on the enzymatic synthesis of labeled glutamic acid and glutamines. J. clin. Invest. 1965, 44, 731.

9. Shalhoub, R., W. Webber, S. Glabman, M. CanessaFischer, J. Klein, J. DeHaas, and R. F. Pitts. Extraction of amino acids from and their addition to renal blood plasma. Amer. J. Physiol. 1963, 204, 181.

10. Van Slyke, D. D., R. A. Phillips, P. B. Hamilton, R. M. Archibald, P. H. Futcher, and A. Hiller. Glutamine as source material of urinary ammonia. J. biol. Chem. 1943, 150, 481.

11. Bartlett, P. D., O. H. Gaebler, and A. Harmon. Studies on the mechanism of nitrogen storage. I. Effects of anterior pituitary growth hormone preparations on plasma glutamine, total free amino acids, and the excretion of urinary ammonia. J. biol. Chem. 1949, 180, 1021.

12. Pitts, R. F., J. DeHaas, and J. Klein. Relation of renal amino and amide nitrogen extraction to ammonia production. Amer. J. Physiol. 1963, 204, 187.

13. Owen, E. E., and R. R. Robinson. Amino acid extraction and ammonia metabolism by the human kidney during the prolonged administration of ammonium chloride. J. clin. Invest. 1963, 42, 263. 